\title{
POLÍTICAS DE EXPANSÃO PARA O ENSINO SUPERIOR NO CONTEXTO DO REUNI: A IMPLEMENTAÇÃO DO PROGRAMA NA UFRN
}

\author{
J. S. SILVA ${ }^{*}$ e A. M. D. A. CASTRO ${ }^{2}$ \\ Universidade Federal do Rio Grande do Norte. \\ josiellesoares@gmail.com
}

Artigo submetido em maio/2014 e aceito em dezembro/2014

DOI: $10.15628 /$ holos.2014.2152

\section{RESUMO}

O presente artigo objetiva investigar as estratégias de expansão para o ensino superior considerando as instituições públicas de ensino, tomando como referência de análise a expansão ocorrida na Universidade Federal do Rio Grande do Norte (UFRN) com a implantação do Programa de Apoio a Planos de Reestruturação e Expansão das Universidades Federais (REUNI). Trata-se de uma pesquisa quali-quantitativa, e utiliza como procedimentos metodológicos a pesquisa bibliográfica e documental, além da análise de dados estatísticos sobre a expansão do ensino superior na UFRN, no período pós REUNI. A pesquisa nos permite inferir que a implantação do REUNI na UFRN trouxe várias modificações na forma de gerenciar os serviços na instituição, tendo em vista a adoção de um modelo de gestão gerencial, ressaltando a adesão ao contrato de gestão. Os dados apresentados demonstram que as metas pactuadas foram atendidas quase que na sua totalidade e algumas até ultrapassadas. A expansão da UFRN é patente, bem como a melhoria das condições físicas e estruturais da instituição. Entretanto, em relação à qualidade, não se pode afirmar que essa vem avançando, uma vez que houve um aumento substancial da relação professor-aluno, o que ratifica que essa expansão também se concretiza via racionalização dos recursos humanos e da estrutura física existentes.

PALAVRAS-CHAVE: Política educacional, Ensino Superior, Expansão.

\section{HIGHER EDUCATION EXPANSION POLICIES IN THE CONTEXT OF REUNI: THE IMPLEMENTATION OF THE PROGRAM IN UFRN}

\begin{abstract}
This article aims to investigate the strategies of expansion of higher education considering the public education institutions, taking as an analysis reference the expansion in the Federal University of Rio Grande do Norte (Universidade Federal do Rio Grande do Norte UFRN) with the introduction of the Federal Universities Restructuring and Expansion Plans Support Program (Programa de Apoio a Planos de Reestruturação e Expansão das Universidades Federais - REUNI. It is a quali-quantitative research that utilizes bibliographical and documental research as methodological procedures, in addition to the analysis of statistical data about the expansion of higher education in UFRN after REUNI. Through the research it is possible to infer that the
\end{abstract}

introduction of REUNI in UFRN has brought various changes in the way of managing the services in the institution, in view of the adoption of a management model, stressing the accession to the management contract. The presented data demonstrate that the goals agreed upon were reached almost in their entirety, and some were even outreached. The expansion of UFRN is evident, as well as the improvement of the physical and structural conditions of the institution. However, in the matter of quality, it is not possible to affirm that there has been progress, given the substantial increase of the professor-student ratio, which confirms that the expansion is also carried through the rationalization of existing human resources and physical structure.

KEYWORDS: Educational policies, Higher Education, Expansion. 


\section{INTRODUÇÃO}

O ensino superior no Brasil tem passado por profundas reformas a partir da aprovação da Lei de Diretrizes e Bases da Educação Nacional (LDB), no 9.394/1996, essas reformas trouxeram modificações significativas na forma de organização do ensino superior, na diversificação do atendimento, na forma de gestão dos serviços educacionais e na autonomia universitária, entre outros. Pode-se considerar que o governo de Fernando Henrique Cardoso (FHC) - no período de 1995 a 2002 - foi o marco dessas mudanças, principalmente por ter adotado as políticas neoliberais na condução dos serviços sociais, realizando uma reforma gerencial para os serviços públicos que passaram a definir nova forma de atuação para as políticas públicas.

Sob o discurso de modernização do ensino superior e seguindo as orientações dos organismos internacionais, o governo federal adotou diferentes estratégias para aumentar a cobertura desse nível de ensino, entre elas: a diversificação institucional permitindo que as instituições universitárias se organizassem com diferentes formatos e a diversificação das fontes de financiamento institucional, aumentando cada vez mais o nível de participação das famílias e das empresas privadas no financiamento desse grau de ensino.

Seguindo o norte dessas políticas e com a crescente necessidade de ampliar o atendimento nas instituições públicas federais, o governo de Luiz Inácio Lula da Silva (2003-2010) aprova o Programa de Apoio a Planos de Reestruturação e Expansão das Universidades Federais (REUNI), pelo Decreto no 6.096/2007, que prevê em suas diretrizes o aumento das vagas de ingresso; a redução das taxas de evasão e a ocupação de vagas ociosas; a ampliação da mobilidade estudantil; a revisão da estrutura acadêmica; a diversificação das modalidades de graduação; a ampliação das políticas de inclusão e assistência estudantil; e a articulação da graduação com a pós-graduação e da educação superior com a básica (BRASIL, 2007a).

O presente artigo analisa a expansão do ensino superior na UFRN tendo como referência a implementação do REUNI. Estrutura-se em quatro partes, a primeira analisa as principais repercussões da reforma do Estado para as políticas do ensino superior da década de 1990. Em seguida, discute as principais orientações dos organismos multilaterais para o referido nível de ensino, tomando como referência documentos elaborados pelo Banco Mundial e pela Organização das Nações Unidas para a Educação, a Ciência e a Cultura (UNESCO). A terceira parte analisa as principais diretrizes do REUNI a partir do Decreto no 6.096/2007 e, em seguida, apresenta os dados referentes à expansão da UFRN no contexto da implementação do REUNI, apresentando algumas considerações finais.

\section{A REFORMA DO ESTADO DA DÉCADA DE 1990 E AS POLÍTICAS PARA O ENSINO SUPERIOR}

Observa-se, nas últimas décadas do século $X X$, uma crise vivenciada pelo sistema capitalista que teve início a partir do final de 1960 e se intensificou a partir de 1973 com a chamada crise do petróleo. Essa crise econômica da década de 1970 contribui para um movimento mundial de reordenação do modelo capitalista vigente, que tem perdurado até o referido momento. Diversos elementos contextuais desencadearam essa crise, dentre os principais, podemos destacar a reestruturação produtiva, o processo crescente de globalização e 
adoção do ideário neoliberal, os quais exigiram a redefinição do papel do Estado com a finalidade de torná-lo mais flexível e reduzido o seu papel na implementação de políticas sociais. Para a superação da crise, foram propostas alternativas neoliberais que se consubstanciaram no marco do Consenso de Washington ${ }^{1}$. Entre as alternativas sugeridas, sobressaem a abertura comercial, a privatização de bens e serviços produzidos pelo Estado, a desregulamentação financeira, redução das despesas e do déficit públicos, supressão dos direitos sociais, entre outras, o que desencadeou uma busca por novas formas de organização dos Estados-nacionais. (ANDERSON, 1995).

O Fundo Monetário Internacional (FMI) passou a recomendar a implementação dessas medidas nos países emergentes na década de 1990, como forma de acelerar o desenvolvimento econômico e difundir as políticas neoliberais. O discurso oficial propagava a necessidade de reforma do Estado com cortes nos gastos públicos sociais e a diminuição da sua dimensão para a superação da crise. Nesse sentido, a lógica do mercado deve-se sobrepor ao Estado para que esse possa ser eficiente e se inserir no processo de globalização, entendido como um fenômeno que exige novas configurações para os Estados nacionais.

Inicia-se, portanto, todo um esforço por parte dos defensores dos ideais neoliberais para a legitimação de uma hegemonia política e econômica defendida, em sua maior parte, por políticos e economistas dos países centrais e por organismos multilaterais, especialmente a partir da década de 1980. Essas mudanças preconizadas pelo capitalismo internacional se institucionalizaram no Brasil no final da década de 1980 e início dos anos de 1990, muito embora, como coloca Minto (2006, p. 213), “[...] a política econômica do regime militar no Brasil indicasse, já em meados dos anos de 1960, uma mudança significativa nos rumos do desenvolvimento capitalista nacional [...]". Esse processo marca o início da readequação do Estado brasileiro aos desígnios do capital internacional e se materializa, em âmbito nacional, nas reformas do Estado brasileiro como um todo.

É, portanto, a partir das eleições presidenciais de 1989, com a predileção de Fernando Collor de Mello, que se inicia a preeminência do tema da reforma do aparelho do Estado no Brasil, surgindo, concomitantemente, a primazia pelo projeto neoliberal de desenvolvimento. No entendimento de Lima (2007, p. 78),

A burguesia brasileira, articulada com o avanço do neoliberalismo, ansiava por uma nova via de desenvolvimento econômico a partir da inserção do país no mercado internacional e pela substituição do modelo desenvolvimentista por novos padrões de acumulação, reivindicando o fim da intervenção estatal no mercado interno e a desregulamentação dos direitos sociais e trabalhistas.

Todavia, pode-se afirmar que o presidente eleito na ocasião não conseguiu construir uma hegemonia política que favorecesse o seu governo na implementação de reformas mais densas no Estado. (MINTO, 2006). Essa nova reorganização do estado brasileiro ganha força e se sistematiza durante os dois governos de FHC - (1995-1998 e 1999-2002) que, fundamentado no ideário do Consenso de Washington, cria, em 1995, o Ministério da Administração Federal e da

\footnotetext{
${ }^{1}$ Caracterizado como um conjunto de medidas formuladas por economistas de instituições financeiras como o Fundo Monetário Internacional (FMI) e o Banco Mundial (BM), no ano de 1989, na capital dos Estados Unidos, o encontro objetivou o estabelecimento de diretrizes neoliberais que passaram a ser um "receituário" para a superação da crise. (ANDERSON, 1995).
} 
Reforma do Estado, que institui o Plano Diretor da Reforma do Estado. Portanto, é nesse período que a reforma do Estado se coloca de maneira imperiosa, torna-se inadiável, segundo o discurso político, para a retomada do crescimento econômico e a melhoria do quadro social do país. Ganham espaço as teses de defesa do mercado, as proposições de Estado mínimo e a redefinição do papel do Estado, passando de executor para regulador das atuais políticas sociais.

A reforma empreendida no contexto dos governos de FHC (1995-2002) tem continuidade com o governo de Luiz Inácio Lula da Silva (2003-2010) e envolveu aspectos políticos, econômicos e administrativos. Ainda nos anos de 1980, foram iniciadas medidas que visavam a aumentar a capacidade de governar (capacidade efetiva do governo para transformar suas políticas em realidade), buscando a estabilidade financeira do Estado através do ajuste fiscal, da privatização, entre outras estratégias.

Na redefinição do papel do Estado, Bresser Pereira (1998) definiu que o novo Estado deveria ter quatro setores: o núcleo estratégico, as atividades exclusivas, os serviços não exclusivos e a produção de bens e serviços para o mercado. O núcleo estratégico (local no qual seriam definidas as leis, as políticas e os regulamentos) seria formado pelo Parlamento, pelos tribunais, pelo presidente ou primeiro ministro, governador e pelos servidores civis dos altos escalões. As atividades exclusivas do Estado, entendidas como as que envolvem o poder do Estado que somente ele pode realizar. Os serviços de educação, saúde, cultura e de pesquisa científica passam a fazer parte das atividades não exclusivas do Estado, as quais podem ser oferecidas pelo setor público, mas também pelo setor privado. E, por fim, a esfera do mercado, na qual estaria a produção de bens e serviços, essas atividades sempre foram vistas como monopólio das empresas privadas, e que, nos últimos anos, vinham sendo assumidas também pelo Estado.

A matriz orientadora das políticas sociais e dentre elas, as educacionais, postas após a reforma do aparelho do Estado, no contexto brasileiro, deriva de uma racionalidade colocada no centro da sociedade no atual estágio do capitalismo, ou seja, quando o capital impõe-se em todas as esferas sociais, determinando o império do setor privado para as diversas instituições, por variados processos. Desse modo, seguindo os preceitos neoliberais, a reforma do Estado, a qual se estabelece como orientadora das reformas educacionais, é apresentada à sociedade como uma estratégia necessária para enfrentar os desafios do mundo contemporâneo.

As influências dessas políticas se fizeram sentir no campo social, em especial na educação que, pela sua própria especificidade de espaço privilegiado na disseminação do saber, desempenha um papel de destaque no desenvolvimento de capacidades e habilidades consideradas básicas pelo capital para a formação de uma mão-de-obra especializada capaz de um melhor desempenho no setor produtivo. A sua adequação às exigências do capital tornou-se, então, uma necessidade. Dessa forma,

[...] condicionado pelo impacto da hegemonia do mercado e pela contenção dos recursos públicos adotados pelo modelo neoliberal, o principal traço das ações foi o de implantar um modelo de reforma do sistema de ensino sem aumentar as despesas, procurando subordinar o sistema às orientações e necessidades prioritárias da economia. (HADDAD, 2003, p. 73).

É necessário ressaltar que a reforma do Estado brasileiro altera significativamente o âmbito da política, da economia e da educação na medida em que propõe reformulações que 
desencadeiam uma nova configuração das políticas e redefine o papel do Estado em relação à gestão de políticas públicas "ao indicar o mercado como regulador das relações entre o âmbito público e privado" (JEZINE, 2008, p. 160). É nessa base orientadora que o ensino superior tem sua reforma implementada. Nesse contexto de reformulações econômicas e políticas são concebidos planos para reestruturar o sistema de ensino superior brasileiro sob diretrizes que atendem determinações internacionais de cunho neoliberal. Dessa forma, as agências multilaterais despontam como os principais agentes do movimento de reformas, que têm como objetivo organizar a economia e a sociedade segundo as orientações neoliberais, no contexto de universalização do capitalismo.

\subsection{DIRETRIZES INTERNACIONAIS E AS DEMANDAS PARA O ENSINO SUPERIOR}

A influência dos organismos internacionais na condução das políticas educacionais brasileiras não é novidade. Carvalho (2007) identifica que essa influência, no caso do Brasil, iniciou-se nos anos de 1960 em que o principal veículo de fundos e de execução da Aliança para o Progresso $^{2}$ foi a Agency for International Development, conhecida como a USAID, a qual se tornou, àquela época, o principal financiador do Brasil. Essa agência passou a proporcionar assistência técnica e cooperação financeira em prol da reorganização do sistema educacional brasileiro por uma série de acordos com o MEC.

Na década de 1990, a agência que se sobressai é o Banco Mundial (BM), fundado em 1944 e tinha como preocupação central o estabelecimento de uma nova ordem mundial, sob a hegemonia norte-americana. As transformações ocorridas no cenário internacional, levaram a um redirecionamento das políticas de investimento do Banco Mundial e suas atividades foram expandidas para os países do Terceiro Mundo, com a finalidade de integrar esse grupo de nações ao bloco ocidental, fortalecendo a aliança não comunista. De 1956 a 1968, os recursos do Banco voltaram-se principalmente para o financiamento da infraestrutura necessária para alavancar o processo de industrialização a que se lançavam diversos países do Sul. Na década de 1970, as ações do Banco Mundial foram influenciadas pelo esgotamento do modelo de acumulação, iniciado no pós-guerra, e pelo surgimento das teorias neoliberais, que passaram a se constituir no seu alicerce ideológico na definição de políticas globais que vêm fundamentando suas ações desde então. (CASTRO, 2001).

No período compreendido entre 1980 e 1995, o Banco Mundial passa por uma reestruturação nas suas funções tendo em vista a crise de endividamento dos países em desenvolvimento. De um Banco que tinha como objetivo fazer investimentos, passa a assumir a responsabilidade de, além de garantir o pagamento da dívida externa, reestruturar e abrir essas economias ao capital globalizado. Dessa forma, passa a exercer uma grande influência nos rumos do desenvolvimento mundial, não só pelo volume de empréstimos, mas pelo caráter estratégico que assumiu no processo de reestruturação neoliberal dos países em desenvolvimento. Uma das medidas adotadas pelo Banco Mundial para operacionalização dos seus novos objetivos foi impor uma série de condicionalidades para a concessão de novos empréstimos aos países devedores,

\footnotetext{
${ }^{2}$ Diz respeito a um programa cooperativo de ajuda norte-americana, direcionado para a América Latina, idealizado na administração Kennedy e implantado nos anos subsequentes. O objetivo era acelerar o desenvolvimento econômico e social da América Latina ao mesmo tempo em que tinha como finalidade frear o avanço do comunismo nesse continente. (CARVALHO, 2007).
} 
usando como instrumental os programas de ajustes estruturais ${ }^{3}$, condicionando empréstimos à realização de imposições feitas pelo Banco.

O BM no documento La enseñanza superior: las lecciones derivadas de la experiência (BANCO MUNDIAL, 1995) recomenda que, para um sistema de educação superior mais equitativo, eficiente e de melhor qualidade, é preciso uma reforma nas fontes de financiamento e na administração desse nível de ensino. Para o empreendimento dessa reforma e para a superação da crise que parece afetar os sistemas de educação superior dos países em desenvolvimento, são dadas as seguintes orientações:

Fomentar maior diferenciação das instituições, incluindo o desenvolvimento de instituições privadas; proporcionar incentivos para que as instituições públicas diversifiquem as fontes de financiamento, por exemplo, a participação dos estudantes nos gastos e a estreita vinculação entre o financiamento fiscal e os resultados; redefinir a função do governo no ensino superior; dotar políticas que priorizem a qualidade e a equidade. (BANCO MUNDIAL, 1995, p. 4, tradução nossa).

Analisando as políticas educacionais que foram implementadas a partir da reforma da educação da década de 1990, é possível identificar que essas orientações foram incorporadas nos marcos legais que determinam a educação brasileira. A Lei de Diretrizes e Bases da Educação Nacional no 9.394/1996 e os decretos dela originados permitem uma grande flexibilização nas formas de organização desse nível de educação e estimulam cada vez mais o investimento da iniciativa privada no setor. Percebe-se, também, um tom de consonância com as recomendações da Organização Mundial do Comércio (OMC) para quem o ensino superior "[...] deveria tornar-se um promissor mercado ou quase mercado de serviços a ser regulamentado no âmbito dos Acordos Gerais do Comércio e Serviços." (SGUISSARD, 2009, p. 209).

As diretrizes do Banco Mundial apresentam propostas que mudam a configuração do ensino superior e estão, de fato, orientando a nova configuração do sistema educacional brasileiro, bem como em âmbito mundial. Algumas dessas propostas são destacadas por Sguissard (2009). A primeira diz respeito ao maior retorno social e individual dos investimentos em educação básica que o dos investimentos em educação superior. Essa proposição objetiva induzir os países em desenvolvimento a focalizarem seus recursos na Educação Básica e, concomitantemente, reduzir os investimentos em educação superior pública e a diversificação de suas fontes de recursos com o fim da gratuidade e imposição de taxas de matrículas e mensalidades. Essa tese é enfatizada em vários documentos do BM, em La enseñanza superior: las lecciones derivadas de la experiência (BANCO MUNDIAL, 1995), por exemplo, se faz elogio ao caso do Chile por ter reduzido os gastos estatais com educação superior.

A segunda tese apresentada se relaciona com a universidade de ensino versus universidade de pesquisa. Nessa proposição, o BM defende o modelo de universidade de ensino, visto que as chamadas universidades de pesquisa de modelo europeu ou humboldtiano são uma das causas da crise do déficit público por causa do comprometimento excessivo do fundo público com esse modelo de universidade. Dessa tese derivam as recomendações para uma maior

\footnotetext{
${ }^{3}$ Denominados SAPs - os ajustes estruturais constituem-se em novas modalidades de empréstimos não vinculadas a projetos mas sujeitos a condicionalidades amplas e severas de cunho macroeconômico e setorial - que passaram a ser geridos pelo Banco Mundial a partir do início dos anos 1980.
} 
diferenciação institucional, incluindo o desenvolvimento de instituições privadas e incentivos para a diversificação de fontes de financiamento. A terceira tese revelada toma o ensino superior antes como bem privado do que público. Nesse caso, o ensino superior estaria apto a se subordinar às forças do mercado, uma vez que não poderia ser tratado exclusivamente como bem público.

No âmbito das políticas para o ensino superior na década de 1990, merece destaque a influência da UNESCO. Criada em 1945, após a Segunda Guerra Mundial, com o objetivo de garantir a paz por meio da cooperação internacional entre as nações, acompanha o desenvolvimento mundial buscando soluções para problemas globais que desafiam as sociedades, atuando nas áreas de Educação, Ciências Naturais, Ciências Humanas e Sociais, Cultura, Comunicação e Informação. A importância do ensino superior para o desenvolvimento dos países é destacada nas Conferências Mundiais. A primeira, em 1998, na qual foi elaborada a Declaração Mundial sobre Educação Superior no Século XXI: Visão e Ação (UNESCO, 1998), que defende a relevância do ensino superior para o desenvolvimento das nações, para a diminuição das desigualdades existentes entre países do norte e do sul e, principalmente, para o progresso socioeconômico e cultural que esse nível de ensino pode proporcionar. A Declaração entende que,

Sem uma educação superior e sem instituições de pesquisa adequadas que formem a massa crítica de pessoas qualificadas e cultas, nenhum país pode assegurar um desenvolvimento endógeno, genuíno e sustentável e nem reduzir a disparidade que separa os países pobres e em desenvolvimento dos países desenvolvidos. (UNESCO, 1998, p. 1).

Dez anos após essa Conferência, é realizada, também em Paris (2009), a segunda Conferência Mundial sobre Ensino Superior organizada pela mesma agência, a UNESCO intitulada As Novas Dinâmicas do Ensino Superior e Pesquisas para a Mudança e o Desenvolvimento Social, que passou a se constituir em outro marco de recomendações para esse nível de ensino e que vem reiterar as diretrizes postas na primeira Declaração de 1998. Nesse novo documento, a UNESCO (2009) coloca o ensino superior como um desafio, sobretudo para os países em desenvolvimento considerando a atual crise econômica.

Diante desse contexto, as estratégias de atuação propostas, trazem as marcas conjunturais que as determinam e estão pautadas em uma diversidade de objetivos que devem ser realizados por diferentes agentes promotores, posto que se trata de um nível de ensino de responsabilidade não apenas de governantes, mas de todos os investidores (UNESCO, 2009). Entre as estratégias que ganham destaque, estão a internacionalização, a regionalização e a globalização, essas são vistas como novas dinâmicas que estão transformando o cenário da educação superior e da pesquisa. Nesse sentido, as parcerias e ações em nível nacional, regional e internacional são vistas como meio de garantir a qualidade dos sistemas de ensino superior. Muitas dessas recomendações postuladas pelo Banco Mundial e pela UNESCO serão acatadas no cerne da atual reforma do ensino superior.

Esses documentos têm orientado as reformas educacionais não só no Brasil, mas em todos os países da América Latina, gerando diretrizes homogeneizadoras, apesar da diversidade cultural, econômica, política e social da região. A reforma educacional, baseada em paradigmas neoliberais, foi estruturada através de um núcleo comum de diagnósticos da situação do 
continente e da apresentação de propostas elaboradas por organismos internacionais aparentemente interessados em encontrar alternativas e soluções para a região, quando, na verdade, seu principal objetivo é mais econômico, ou seja, garantir o pagamento da dívida externa dos países em desenvolvimento com outros países, sobretudo os Estados Unidos.

De acordo com Ribeiro e Chaves (2011, p. 129), as diretrizes dos organismos multilaterais influenciaram a reconfiguração da educação superior brasileira, a qual vem, lentamente, alterando a natureza das instituições através de marcos normativos. Dentre as recentes medidas, as autoras destacam o Programa de Apoio a Planos de Reestruturação e Expansão das Universidades Brasileiras, instituído pelo Decreto no 6.096/2007 (BRASIL, 2007a), o qual estabelece modificações substanciais na organização das universidades alterando de forma direta o modelo de gestão dessas instituições.

\section{O PROGRAMA DE APOIO A PLANOS DE REESTRUTURAÇÃO E EXPANSÃO DAS UNIVERSIDADES FEDERAIS (REUNI): ALGUMAS ANÁLISES}

Nos últimos anos presencia-se a adoção pelo governo federal de políticas educativas que têm fomentado a expansão do ensino superior. Essas políticas podem ser evidenciadas em três tendências distintas, a expansão pela privatização do ensino, a expansão pelo uso da modalidade a distância e a expansão pela reestruturação das universidades públicas federais. No contexto das universidades públicas federais, o governo vem orientando a expansão do ensino em uma lógica racional dos recursos físicos e humanos existentes.

Essa política tem-se operacionalizado por meio do Programa de Apoio a Planos de Reestruturação e Expansão das Universidades Federais (REUNI), aprovado pelo MEC por meio do Decreto no 6.096 de 24 de abril de 2007 (BRASIL, 2007a), concebido como parte do Plano de Desenvolvimento da Educação (PDE) ${ }^{4}$.

Esse Plano apresenta um conjunto de ações consideradas prioritárias para o governo federal. Lima (2008) destaca nove ações do Plano que estão diretamente ligadas com a educação superior:
1) Universidade Aberta do Brasil/UAB; 2) Fundo de Financiamento ao Estudante do Ensino Superior (FIES); 3) Programa Nacional de Pós-doutorado; 4) Programa Incluir: Acessibilidade na Educação Superior; 5) Apoio Financeiro à produção de conteúdos educacionais digitais multimídias; 6) PROEXT; 7) Nova Coordenação de Aperfeiçoamento de Pessoal de Nível Superior (CAPES); 8)Programa REUNI; e 9) Banco de Professores-equivalente. (BRASIL, MEC/MPOG apud LIMA, 2008, p. 72, grifo nosso).

No que se refere ao REUNI, o Programa tem sido destaque das políticas do governo federal, utilizando-se do discurso de expansão e democratização do ensino superior no Brasil. Sua proposta de diversificação dos cursos de graduação encontra grandes semelhanças com as

\footnotetext{
${ }^{4}$ O Plano de Desenvolvimento da Educação (PDE) foi lançado oficialmente em 24 de abril de 2007, concomitante à promulgação do Decreto no 6.094 que dispõe sobre o "Plano de Metas Compromisso Todos pela Educação", considerado o carro-chefe do PDE. "Trata-se, com efeito, de ações que cobrem todas as áreas de atuação do MEC, abrangendo os níveis e modalidades de ensino, além de medidas de apoio e infraestrutura". (SAVIANI, 2007, p. 1232).
} 
políticas elaboradas pelo Banco Mundial para os países da periferia do capitalismo. O REUNI estabelece que as relações entre as universidades e o governo federal sejam regidas por um contrato de gestão, essa é uma das formas que o governo brasileiro encontrou, no âmbito da reforma, para gerenciar os serviços públicos, inclusive as universidades, estabelecendo metas e indicadores possíveis de serem acompanhadas e avaliadas, dando, assim, continuidade à proposta apresentada em 1995 pelo Ministério da Administração Federal e Reforma do Estado (MARE). Essa forma de contrato tem por finalidade alcançar melhores resultados administrativos sob um discurso de maior autonomia para as instituições. O objetivo da celebração do contrato de gestão, em relação às empresas estatais, segundo Di Pietro (1996, s.p) é o de fixar compromissos bilaterais:

a) para a empresa ou órgão, o de cumprir determinados objetivos fixados em planos nacionais ou em programas pré-definidos pelas partes; b) para a Administração Pública, o de flexibilizar os meios de controle sobre a entidade, conferindo-Ihe maior grau de autonomia na gestão dos negócios.

Nesse caso, o contrato de gestão, de acordo com a autora, seria utilizado com o objetivo de controle administrativo, tendo em vista que submete as empresas ao cumprimento dos programas ou objetivos governamentais. A reestruturação das universidades federais, por essa via, implica numa autonomia bastante relativa, numa autonomia controlada pelo Estado e pelo mercado. Como revelam Catani e Oliveira (2000, p. 108), “[...] ela [a autonomia] se insere no processo de minimização do Estado e, portanto, de limitação dos fundos públicos no tocante ao financiamento das políticas públicas". Vê-se, portanto, uma subordinação em relação à redefinição dos espaços público e privado perante uma necessidade estrutural de expansão do atual sistema capitalista.

O decreto que institui o REUNI é composto por oito artigos e lança as bases para transformações significativas na estrutura das universidades públicas brasileiras em um contexto claro de expansão da educação superior. Além do Decreto no 6.096/2007, foi lançado um documento, intitulado Diretrizes Gerais do REUNI (BRASIL, 2007b), expondo os principais pontos do Programa, buscando esclarecer e orientar as universidades em relação às diretrizes a serem observadas pelas instituições na elaboração de seus planos de reestruturação. No que concerne ao ensino superior público, o REUNI passa a ser a grande política do governo federal, representado em um programa de ampla dimensão nos campos acadêmico, político e estratégico.

O Programa foi instituído como forma de induzir as universidades públicas federais a estabelecerem contratos de gestão, por meio de termo de compromisso chamado de Acordo de Metas, impondo às instituições o cumprimento das etapas explícitas em seus planos para receberem verbas públicas. Dessa forma, cada universidade ficou responsável pela elaboração do seu plano de reestruturação especificando as estratégias e etapas que devem ser cumpridas ao longo dos cinco anos. Chaves e Mendes (2009, p. 57) chamam atenção que

Tal acordo segue a lógica gerencial da administração por resultados, a estes vinculando o repasse de recursos orçamentários, dependente do cumprimento de metas por etapas, dentro de prazos estabelecidos por meio de indicadores quantitativos. 
Nessa lógica, o REUNI condiciona o financiamento ao cumprimento de metas previamente acordadas nos Contratos de Gestão. De acordo com o decreto, "A proposta, se aprovada pelo Ministério da Educação, dará origem a instrumentos próprios, que fixarão os recursos financeiros adicionais destinados à universidade, vinculando os repasses ao cumprimento das etapas." (Art. 60, BRASIL, 2007a, grifo nosso). Além disso, ainda conforme o decreto, os repasses financeiros dependem da capacidade orçamentária do MEC, como está circunscrito no terceiro parágrafo do artigo 3o: "O atendimento dos planos é condicionado à capacidade orçamentária e operacional do Ministério da Educação". (BRASIL, 2007a). Sendo assim, percebe-se que os recursos destinados a essa expansão são restritos, o que pode comprometer a qualidade da expansão nesse nível de ensino.

A análise dos aspectos jurídicos do referido decreto aponta, segundo Tonegutti e Martinez (2008, p. 63), para a sua ilegalidade caso a sua aplicação demande aumento de despesa,

Nesse sentido, temos que a Constituição Federal, em seu art. 84, inciso VI, alínea a, estabelece que os decretos do Presidente da República podem dispor sobre organização e funcionamento da administração federal, quando não implicar aumento de despesa nem criação ou extinção de órgãos públicos (grifos dos autores).

Para se resguardar desse elemento jurídico, o próprio texto do decreto, no seu art. 7ํㅡ, faz uma ressalva para assegurar sua constitucionalidade, "As despesas decorrentes deste decreto correrão à conta das dotações orçamentárias anualmente consignadas ao Ministério da Educação" (BRASIL, 2007a). Isso indica que o financiamento do REUNI deve ocorrer por remanejamento nominal de recursos, já previstos no plano plurianual em vigor, já que recursos novos demandariam projeto de lei específico. (TONEGUTTI; MARTINEZ, 2008).

O objetivo principal do Programa é "criar condições para a ampliação do acesso e permanência na educação superior, no nível de graduação." (Art. 1ํ, BRASIL, 2007a). Nesse primeiro artigo do decreto, fica claro que esse objetivo deverá ser alcançado por um melhor aproveitamento dos recursos já existentes nas universidades, tanto no que diz respeito à estrutura física quanto aos recursos humanos. Portanto, logo de início, o decreto esclarece que, para alcançar sua finalidade, a racionalização dos recursos deverá ser utilizada. Quanto a esse assunto, Cislaghi (2011) analisa que essa perspectiva racionalizadora advém de diretrizes do Banco Mundial:

O objetivo do Programa [...] [se insere] em uma clara perspectiva racionalizadora, que parte do princípio, coincidente com o do Banco Mundial, de que há subaproveitamento nas universidades federais, diagnóstico presente no Brasil desde a reforma universitária da ditadura militar. (CISLAGHI, 2011, p. 166).

Para a concretização do objetivo, o Programa estabelece duas metas globais que estão especificadas no primeiro parágrafo do artigo 10 do decreto. A primeira se refere à elevação gradual da taxa de conclusão média dos cursos de graduação presenciais para $90 \%$ e a segunda meta faz referência ao aumento da relação de alunos de graduação em cursos presenciais por professor para dezoito, ao final de cinco anos, contados do início de cada plano. 
Para que o REUNI atinja seus objetivos e metas, o artigo 20 do decreto apresenta as seguintes diretrizes: I - redução das taxas de evasão, ocupação de vagas ociosas e aumento de vagas de ingresso, especialmente no período noturno; II - ampliação da mobilidade estudantil, com a implantação de regimes curriculares e sistemas de títulos que possibilitem a construção de itinerários formativos, mediante o aproveitamento de créditos e a circulação de estudantes entre instituições, cursos e programas de educação superior; III - revisão da estrutura acadêmica, com reorganização dos cursos de graduação e atualização das metodologias de ensino-aprendizagem, buscando a constante elevação da qualidade; IV - diversificação das modalidades de graduação, preferencialmente não voltadas à profissionalização precoce e especializada; $V$ - ampliação de políticas de inclusão e assistência estudantil; e VI articulação da graduação com a pós-graduação e da educação superior com a educação básica. (BRASIL, 2007a).

Conforme o decreto, em seu artigo 4은,

O plano de reestruturação da universidade que postule seu ingresso no Programa, respeitados a vocação de cada instituição e o princípio da autonomia universitária, deverá indicar a estratégia e as etapas para a realização dos objetivos referidos no art. 1‥ (BRASIL, 2007a).

Nesse ponto, é interessante questionar se realmente está sendo respeitado o princípio de autonomia universitária, aspecto tão relevante para a construção da universidade enquanto espaço de formação crítica e cidadã, uma vez que é o decreto que estabelece as metas que a universidade terá de cumprir, como está posto no primeiro parágrafo do artigo 10 (elevação da taxa de conclusão média dos cursos de graduação para noventa por cento e da relação de alunos de graduação por professor para dezoito). No ano de 2007, por exemplo, a relação de alunos de graduação dos cursos presenciais por professor das universidades federais era de $10,8 \%$. Esse indicador tem estreita relação com a ampliação de vagas e, de modo geral, as críticas em relação ao aumento dessa relação foram intensas, tendo em vista a possibilidade de intensificação e precarização do trabalho docente.

Além disso, o MEC também impõe as estratégias de controle e acompanhamento que condicionam a alocação de verbas do Programa, as quais estão especificadas no documento das Diretrizes do REUNI:

O processo de acompanhamento da execução das metas propostas pelas universidades integrantes do REUNI será realizado por meio da Plataforma PingIFES, cujo objetivo consiste na coleta de informações sobre a vida acadêmica das instituições federais de ensino superior. Seus dados são utilizados na distribuição de recursos orçamentários das IFES [...]. Com o horizonte fixado pelas metas relativas à abertura de novas vagas, às taxas de conclusão dos cursos e ao aumento gradativo da relação entre o número de alunos e professor estabelecidas nos projetos de cada universidade aderente, o PingIFES oferecerá o instrumental necessário para o desenvolvimento do processo de acompanhamento [...]. Além disso, o processo de verificação das informações incorporará a extensa gama de dados coletados por diversos órgãos (INEP, CAPES), inserindo-se, ainda, no contexto do sistema de avaliação estabelecido pelo SINAES. Assim, a integração dos resultados das diferentes dimensões da avaliação [...] deve ser efetuada para que se tenha uma adequada aferição das mudanças ocorridas a partir da adesão ao REUNI. (BRASIL, 2007b, p.9 ). 
Portanto, analisamos que autonomia a que o REUNI se refere é facetada, pois a expansão preconizada pelo Programa não foi pensada e discutida pela comunidade universitária, ao contrário, foi imposta pela "visão" limitada de um decreto e será controlada e acompanhada, conforme indicam as Diretrizes. Sendo assim, a autonomia universitária será exercida apenas no que diz respeito à adesão ou não ao Programa, ou seja, à liberdade para atender aos objetivos oficiais.

Cabe destacar que o Decreto $\mathrm{n}$ - 6.096/2007, em nenhum momento, faz menção à articulação entre ensino, pesquisa e extensão, própria das universidades e definida no artigo 207 da Constituição Federal de 1988 (BRASIL, 1988) e no artigo 52 da LDB no 9.394/1996 (BRASIL, 1996). O documento das Diretrizes Gerais (BRASIL, 2007b) também negligencia a indissociabilidade entre os eixos ensino, pesquisa e extensão. Faz uma única menção à palavra extensão quando se refere às "Políticas de extensão universitária", como uma dimensão do compromisso social da instituição.

Nesse sentido, compreende-se que a expansão preconizada pelo REUNI está privilegiando apenas a dimensão do ensino, negligenciando que as universidades atuam não só no âmbito do ensino, mas na pesquisa e extensão. Isso pode implicar em precarizar o nível científico e tecnológico, principalmente das universidades que não possuem a pesquisa e a extensão fortemente consolidadas.

\section{EXPANSÃO NA UFRN NO CONTEXTO DO REUNI}

A implantação do REUNI nas universidades públicas está diretamente articulada às mudanças na forma de gestão e à consequente reorganização dos serviços públicos. Nesse sentido, torna-se evidente a tentativa de promover uma expansão pela via da racionalização dos recursos, como está posto no próprio decreto que institui o Programa, e introduzir uma lógica gerencialista voltada para o controle de resultados nas universidades federais. Esse processo, na UFRN, implicou, conforme os ditames do Decreto no 6.096/2007, no estabelecimento de um plano de metas, explicitado em um contrato de gestão. A instituição aderiu ao Programa no ano de 2007 e construiu sua proposta baseada em alguns debates realizados nos Centros e Unidades Acadêmicas, contando com a participação dos segmentos da comunidade acadêmica.

Conforme pesquisa realizada por Pereira (2012), já havia um plano de expansão para a UFRN antes do REUNI, explicitado no Plano de Desenvolvimento Institucional - PDI (2005-2019), porém sem muitas expectativas, pois não existia a garantia de recursos financeiros para colocar as metas em prática, era um plano elaborado pela comunidade acadêmica para atender às demandas da UFRN naquela época. Com a chegada do REUNI, foi necessário elaborar um novo plano institucional, mais adequado ao perfil gerencialista que passou a ser exigido pelo MEC para as instituições públicas.

A novidade que o REUNI trouxe se mostrou na possibilidade de ampliação dos recursos financeiros e humanos, caso as universidades concordassem em atingir as metas e objetivos do Programa, introduzindo, desse modo, um novo paradigma de gestão em âmbito público. Esse novo modelo de gestão, orientado pela racionalidade do capital e subordinado à lógica economicista, faz parte do cenário de reformas do aparelho do Estado brasileiro em que a 
educação de nível superior é um importante setor que precisa ser reestruturado com a finalidade de se adequar aos interesses do sistema capitalista. (RIBEIRO; CHAVES, 2010).

A proposta de reestruturação e expansão apresentada pela UFRN expõe metas no âmbito das seis dimensões do Programa REUNI: ampliação da oferta no ensino superior; reestruturação acadêmico-curricular; renovação pedagógica; mobilidade intra e interinstitucional; compromisso social da instituição; e suporte da pós-graduação ao desenvolvimento e aperfeiçoamento qualitativos dos cursos de graduação. (UFRN, 2007). Esse plano de reestruturação começa expondo as características atuais da instituição, expressando alguns números que traduzem a sua importância no contexto socioeconômico e cultural do estado do Rio Grande do Norte. Destaca ainda, que a adesão ao Programa de Apoio a Planos de Reestruturação e Expansão das Universidades Federais poderá ser uma importante estratégia institucional para a UFRN, no que se refere à melhoria da qualidade acadêmica. A implementação do REUNI na Universidade Federal do Rio Grande do Norte, provocou várias modificações em todas as suas esferas administrativas e pedagógicas. Ao aderir ao Projeto proposto pelo governo federal, a Universidade assumia uma nova forma de gestão e a busca por estratégias diversificadas de atendimento.

Conforme o relatório do REUNI-UFRN 2008-2012 (UFRN, 2013), no Acordo de Metas celebrado entre a UFRN e o Ministério da Educação foram pactuadas 12.798 matrículas projetadas nos cursos de graduação presenciais no período de 2008-2012. Objetivando atingir essa meta, a instituição criou 39 cursos de graduação regulares e presenciais no período de 20072012. A tabela 01 permite observar como foram distribuídos os cursos novos na UFRN, considerando o turno e a área do conhecimento, segundo a classificação da Coordenação de Aperfeiçoamento de Pessoal de Nível Superior (CAPES) e Conselho Nacional de Desenvolvimento Científico e Tecnológico (CNPq).

Tabela 01: Novos cursos criados na UFRN, no período de 2007-2012, por turno e área do conhecimento

\begin{tabular}{|l|c|c|}
\hline \multirow{2}{*}{ Áreas do conhecimento } & \multicolumn{2}{|c|}{ Turnos } \\
\cline { 2 - 3 } & Diurno & Noturno \\
\hline Ciências Exatas e da Terra & 4 & - \\
\hline Engenharias & - & 4 \\
\hline Ciências da Saúde & 4 & 2 \\
\hline Ciências Agrárias & 3 & - \\
\hline Ciências Sociais Aplicadas & - & 1 \\
\hline Ciências Humanas & 1 & 3 \\
\hline Linguística, Letras e Artes & 3 & - \\
\hline Multidisciplinar/Outros & 1 & 2 \\
\hline Cursos sem definição de área pela CAPES e CNPq & 7 & 4 \\
\hline Total de cursos por turno & 23 & 16 \\
\hline
\end{tabular}

Fonte: CONSEPE através do Relatório REUNI 2008-2012.

A tabela demonstra que foram criados trinta e nove (39) cursos em todas as áreas do conhecimento, exceto em Ciências Biológicas. A predominância se destaca nos cursos que não se encaixam nas áreas definidas tradicionalmente pela CAPES e pelo CNPq, com onze (11) cursos ao todo, distribuídos nos turnos diurnos sete (07) cursos e quatro (04) cursos no noturno. A segunda área com mais cursos criados foi a de Ciências da Saúde, com seis cursos 04 diurnos e 02 diurnos. 
A área de Ciências Exatas e da Terra, Ciências Humanas e Engenharias concentram a criação de quatro cursos cada uma, sendo que nas Engenharias todos os cursos estão no turno noturno, enquanto nas Ciências Exatas e da Terra os cursos se agrupam no turno diurno. Na área das Ciências Humanas há um (01) curso diurno e três (03) noturnos. As áreas de Ciências Agrárias, Multidisciplinar/Outros e Linguística, Letras e Artes agregam um total de três (03) cursos cada uma, os de Ciências Agrárias são todos diurnos, ao passo que na área Multidisciplinar/Outros há um (01) curso diurno e dois (02) noturnos e em Linguística, Letras e Artes os três (03) cursos estão no turno diurno. Por fim, temos as Ciências Sociais Aplicadas que apresentam a criação de um (01) curso no turno noturno. Ao todo, somam-se 23 cursos diurnos e 16 noturnos.

Chamamos atenção para o fato de que a maioria dos cursos criados foi da área do conhecimento ainda não definida pela CAPES ou CNPq, grande parte, são cursos no campo das novas tecnologias. Essa é uma possível estratégia da UFRN para promover cursos que propiciem uma maior inovação científica e tecnológica e permitam à instituição melhorar seu ranking entre as universidades do país. Esses cursos criados sem classificação de área são: Ciências e Tecnologia (diurno e noturno), Engenharia de Petróleo (diurno), Engenharia de Telecomunicações (noturno), Tecnologia da Informação (diurno e noturno), Análise e Desenvolvimento de Sistemas (diurno), Engenharia Ambiental (diurno), Gestão de Políticas Públicas (diurno e noturno) e Design (diurno).

Os referidos cursos se encaixam também nas novas diretrizes do ensino superior em uma sociedade marcada pela emergência de um novo paradigma econômico e produtivo, que destaca a importância do conhecimento e da informação para a expansão do capital, como uma estratégia que possibilita a maior participação dos países no mercado competitivo. Nessa perspectiva há uma maior exigência na eficiência dos sistemas de formação de trabalhadores altamente qualificados para atender à demanda dos mercados, cobra-se a investigação, o desenvolvimento e a inovação.

A urgência por inovação é declarada, por exemplo, no documento do BM Conhecimento e Inovação para a Competitividade (BANCO MUNDIAL, 2008), traduzido pela Confederação Nacional da Indústria (CNI) o qual parte do pressuposto de que o conhecimento, no novo paradigma de produção capitalista, é fundamental para gerar um alto crescimento no atual mundo globalizado e competitivo. Desse modo, a capacidade tecnológica e a inovação ganham maior importância em detrimento dos recursos naturais o dos fatores básicos de produção.

O documento, dentre outros elementos, compara a evolução das economias de países que investiram em pesquisa e desenvolvimento, ou seja, adotando a estratégia de desenvolvimento impulsionado pelo conhecimento. Recomenda que os países em desenvolvimento devam investir pesadamente em inovação e educação de qualidade em todos os níveis para que possam competir com economias avançadas.

Há uma preocupação de que o Brasil está preparado de modo inadequado para competir em um mundo cada vez mais globalizado e de que, apesar dos avanços na abordagem de graves deficiências nas últimas décadas, o sistema de educação continue a ser pouco produtivo. (BANCO MUNDIAL, 2008, p. 193).

Nessa perspectiva, inferimos que a UFRN vem atendendo às diretrizes elaboradas em nível nacional e supranacional para a expansão do ensino superior e a inovação imposta com o surgimento da chamada economia do conhecimento. Verificamos, portanto, que há um esforço 
não só para a expansão do ensino superior, mas também em atender às exigências concernentes às mudanças que ocorreram nos últimos anos na natureza do trabalho, que demanda cada vez mais um profissional capaz de lidar com as novas tecnologias e produzir inovação para a competitividade.

Em relação à expansão quantitativa ocorrida no âmbito da UFRN, podemos verificar, na tabela 02, a sua evolução, considerando o número de cursos, vagas, matrículas e alunos diplomados, no período 2008-2012.

Tabela 02:Indicadores e dados globais pactuados e realizados da graduação, conforme Acordo de Metas da UFRN 2008-2012

\begin{tabular}{|c|c|c|c|c|c|c|c|c|c|c|c|}
\hline \multirow{2}{*}{$\begin{array}{l}\text { Indicadores } \\
\text { graduação }\end{array}$} & \multirow{2}{*}{ da } & \multicolumn{2}{|l|}{2008} & \multicolumn{2}{|l|}{2009} & \multicolumn{2}{|l|}{2010} & \multicolumn{2}{|l|}{2011} & \multicolumn{2}{|l|}{2012} \\
\hline & & $\begin{array}{l}\text { Pactua- } \\
\text { dos }\end{array}$ & $\begin{array}{l}\text { Realiza- } \\
\text { dos }\end{array}$ & $\begin{array}{l}\text { Pactua- } \\
\text { dos }\end{array}$ & $\begin{array}{l}\text { Realiza- } \\
\text { dos }\end{array}$ & $\begin{array}{l}\text { Pactua- } \\
\text { dos }\end{array}$ & $\begin{array}{l}\text { Realiza- } \\
\text { dos }\end{array}$ & $\begin{array}{l}\text { Pactua- } \\
\text { dos }\end{array}$ & $\begin{array}{l}\text { Realiza- } \\
\text { dos }\end{array}$ & $\begin{array}{l}\text { Pactua- } \\
\text { dos }\end{array}$ & $\begin{array}{l}\text { Realiza- } \\
\text { dos }\end{array}$ \\
\hline \multirow{2}{*}{$\begin{array}{l}\text { Número de } \\
\text { cursos }\end{array}$} & Total & 77 & 86 & 98 & 104 & 99 & 105 & 102 & 107 & 106 & 119 \\
\hline & Noturno & 19 & 20 & 32 & 32 & 33 & 33 & 33 & 33 & 37 & 37 \\
\hline \multirow{2}{*}{$\begin{array}{l}\text { Vagas } \\
\text { anuais }\end{array}$} & Total & 4.263 & 4.169 & 6.049 & 5.805 & 6.642 & 6.467 & 6.807 & 6.937 & 7.112 & 7.201 \\
\hline & Noturno & 1.014 & 994 & 1.959 & 1.902 & 2.259 & 2.246 & 2.260 & 2.415 & 2.520 & 2.549 \\
\hline \multirow{2}{*}{$\begin{array}{l}\text { Matrícula } \\
\text { projetada }\end{array}$} & Total & 20.600 & 20.124 & 28.381 & 27.169 & 30.562 & 29.429 & 31.452 & 31.614 & 33.028 & 32.894 \\
\hline & Noturno & 4.669 & 4.578 & 8.718 & 8.471 & 9.797 & 9.676 & 9.797 & 10.478 & 11.168 & 11.171 \\
\hline \multirow{2}{*}{$\begin{array}{l}\text { Alunos } \\
\text { diplomados }\end{array}$} & Total & 2.797 & 2.892 & 2.900 & 3.037 & 3.083 & 2.928 & 3.278 & 2.803 & 5.145 & 3.205 \\
\hline & Noturno & 719 & 707 & 738 & 669 & 770 & 675 & 786 & 699 & 1.681 & 795 \\
\hline
\end{tabular}

Fonte: Relatório REUNI-UFRN 2008-2012 (2013).

A tabela 02 permite que se comparem as metas pactuadas pela instituição e as metas realizadas. No que se refere ao número de cursos podemos observar que em todos os anos a meta foi atingida e ultrapassou o número de cursos pactuados. 0 ano de 2012 foi o que alcançou o maior índice, pois no planejamento institucional, intencionava-se atingir, em 2012, 106 cursos funcionando e essa meta foi ultrapassada chegando a 119 cursos. No que se refere aos cursos noturnos, as metas pactuadas foram cumpridas, mas não houve nenhum excedente. Em relação às vagas apenas a partir do ano de 2011 é que a instituição consegue atingir e superar a meta acordada. Quanto às vagas noturnas, somente em 2012 o objetivo é atingindo. Considerando as matrículas projetadas para o período 2008-2012, a UFRN pactuou em seu Acordo de Metas um total de 12.798 novas matrículas e realizou 12.664 gerando um déficit de 134 matrículas em relação ao que foi acordado, porém o que foi pactuado de matrículas noturnas foi cumprido. Considerando o crescimento total das matrículas no final do período, observa-se que a UFRN saltou de 20.124 matrículas em 2008 para 32.894 em 2012, o que representou um aumento total de $60 \%$ nas matrículas da instituição.

Quanto ao número de alunos diplomados, observa-se que, nos anos de 2008 e 2009, as metas foram atingidas, no entanto, o mesmo não ocorreu com as metas previstas para os cursos noturnos, embora a diferença entre o pactuado e alcançado seja muito pequena. Já nos anos subsequentes 2010, 2011 e 2012, os dados mostram que a UFRN não conseguiu atingir a meta pactuada em relação ao número de alunos diplomados e que o ano de 2012 registra uma diferença de 2.120 alunos que não conseguiram se diplomar nos cursos diurnos. Nos cursos 
noturnos, a meta também não foi alcançada e a diferença é de 886 discentes. Esse não atingimento da meta de alunos diplomados tem levado a instituição a rever sua política de avaliação dos discentes, com propostas que têm reduzido a média de aprovação. Essa medida futuramente poderá repercutir no desempenho dos alunos e na classificação final de avaliação dos cursos.

Em relação a esses dados apresentados, considera-se que houve um esforço da instituição para o cumprimento das metas pactuadas por ocasião do REUNI e que várias estratégias foram utilizadas para aumentar a oferta de matrículas, entre elas, merece destaque a expansão dos cursos na modalidade da educação a distância que, em 2007, registrava um total de 2.586 matriculas, passando, em 2012, para 4.432 matrículas, o que representou um crescimento percentual aproximado de $71 \%$.

Considerando as duas metas globais determinadas no Decreto no 6.096/2007, a elevação gradual da taxa de conclusão média dos cursos de graduação presenciais para $90 \%$ e o aumento da relação do número de alunos da graduação por professor para 18/1, conforme o relatório REUNI-UFRN 2008-2012, podemos concluir que, no que diz respeito à primeira meta global, a instituição não atingiu o estabelecido no Acordo em nenhum ano do período do REUNI, tendo, ao final de 2012, alcançado uma taxa de conclusão dos cursos de graduação de $82 \%$, havendo, no entanto, uma elevação gradual considerável de $15 \%$ em relação ao ano de 2008 . Quanto ao aumento da relação professor/aluno essa meta foi plenamente atingida, chegando a ultrapassar, no ano de 2011, o previsto no decreto, numa relação de 19,18 alunos por professor.

Pelos dados apresentados pode-se evidenciar que a UFRN fez um esforço para cumprir as metas pactuadas e que houve uma expansão muito grande nos cursos e nas matrículas da instituição. Pode-se dizer que o REUNI é um programa bem sucedido do ponto de vista de ampliação do acesso dos alunos ao ensino superior público. O Programa vem possibilitando aumentar cada vez mais o número de alunos nesse nível de ensino, por meio da implementação de várias estratégias que estão articuladas às diretrizes dos organismos internacionais. Essas diretrizes evidenciam em seus pressupostos a necessidade de expansão desse nível de ensino, a utilização de novas formas de gestão e financiamento e a utilização de novas modalidades educacionais.

\section{CONSIDERAÇÕES FINAIS}

O processo de expansão das universidades públicas federais foi estabelecido em normatizações provenientes de decisões centralizadas e estabelecidas com base em pressupostos que contemplavam, por um lado, a racionalização dos espaços físicos e humanos já existentes nas universidades públicas e por outro evidenciava a construção de novos espaços físicos, contratação de técnicos e docentes, abertura de novas vagas e matrículas.

Os pressupostos assumidos estão em articulação com as tendências nacionais e internacionais para a educação superior que apontam para a necessidade de expansão desse nível de ensino, para novas formas de gestão e financiamento ao mesmo tempo em que também apontam para a redução do financiamento público em educação, em uma perspectiva neoliberal para as políticas sociais. 
No contexto de expansão da educação superior, o REUNI concretiza-se como uma estratégica medida do governo para a reestruturação desse nível de ensino, o qual insere a universidade brasileira numa nova lógica administrativa que desconsidera a autonomia da instituição. O Programa promove uma expansão que se dá tanto pela ampliação da rede física como pela via da racionalização, pela otimização dos recursos humanos e dos espaços físicos existentes, introduzindo um paradigma de gestão gerencialista voltado para o controle dos resultados nas universidades. O REUNI trouxe várias modificações na forma de gerenciar os serviços na instituição, tendo em vista a adoção de um modelo de gestão gerencial, ressaltando a adesão ao contrato de gestão. Segundo essa lógica, a universidade se torna mais ágil em relação aos processos, buscando a eficiência e eficácia dos seus serviços.

Com a implantação do REUNI percebe-se que há uma nova dinâmica de expansão na UFRN. A expansão ocorreu tanto nas matrículas, como nas vagas e na criação dos cursos. A análise dos dados demonstra que as metas pactuadas foram atendidas quase que na sua totalidade e algumas até ultrapassadas. A expansão da UFRN é patente, bem como a melhoria das condições físicas e estruturais da instituição. Entretanto, em relação à qualidade, não se pode afirmar que essa vem avançando, uma vez que houve aumento substancial da relação professoraluno, flexibilização dos processos avaliativos e nas estruturas curriculares.

É importante compreender que as reformulações na política educacional de ensino superior estão atreladas a um amplo movimento de reordenação do capital que vem colocando a educação como setor de serviços não exclusivo do Estado, desconsiderando que a educação é um bem público e que deve ser direito de todos.

\section{REFERÊNCIAS BIBLIOGRÁFICAS}

1. ANDERSON, Perry. Balanço do neoliberalismo. In: SADER, Emir; GENTILI, Pablo (Org.). Pósneoliberalismo: as políticas sociais e o estado democrático. 4. ed. Rio de Janeiro: Paz e Terra, 1995.

2. BANCO MUNDIAL. La enseñanza superior: las lecciones derivadas de la experiência, Washington, DC, 1995.

3. Conhecimento e inovação para a competitividade. Tradução: Confederação Nacional da Indústria. Brasília: CNI, 2008.

4. BRASIL. Constituição (1988). Constituição da República Federativa do Brasil de 1988. Brasília, DF: Senado $1988 . \quad$ Federal, Disponível em: <http://www.planalto.gov.br/ccivil_03/constituicao/constituicao.htm>. Acesso em: 15 jun. 2013.

5. ___ Lei no 9.394 de 20 de dezembro de 1996. Estabelece as diretrizes e bases da educação nacional, $1996 . \quad$ Disponivel em: <http://www.planalto.gov.br/ccivil_03/leis/I9394.htm>. Acesso em: 17 junho 2013.

6. Decreto no 6.096, de 24 de abril de 2007a. Institui o Programa de Apoio a Planos de Reestruturação e Expansão das Universidades Federais - REUNI, 2007a. Disponivel em: <http://www.planalto.gov.br/ccivil_03/_ato2007-2010/2007/decreto/d6096.htm>. Acesso em: 18 junho 2013.

7. . Ministério da Educação e do Desporto. Diretrizes Gerais do Decreto 6.096 - REUNI - 
Reestruturação e Expansão da Universidades Federais, Disponível em: , 2007b. Disponivel em: <http://portal.mec.gov.br/sesu/arquivos/pdf/diretrizesreuni.pdf>. Acesso em: 17 jun. 2013.

8. BRESSER PEREIRA. Luiz Carlos. Reforma do estado para a cidadania: a reforma gerencial brasileira na perspectiva internacional. São Paulo: Ed. 34; Brasília: ENAP, 1998.

9. CARVALHO, Cristina Helena Almeida de. Agenda neoliberal e a política para o ensino superior nos anos 90. Diálogo Educação, Curitiba, v.7, maio/ago. 2007. p. 83-101.

10. CASTRO, Alda Maria Duarte Araújo. Accoutability e empoderamento: estratégias gerenciais na escola, 2001.20 Disponível <www.anpae.org.br/congressos_antigos/simposio2007/12.pdf> Acessado em 25 fev. 2014.

11. CATANI, Afrânio Mendes; OLIVEIRA, João Ferreira. A reforma da educação superior no Brasil nos anos 90: diretrizes, bases e ações. In: CATANI, Afrânio Mendes; OLIVEIRA, Romualdo Portela de. Reformas educacionais em Portugal e no Brasil. Belo Horizonte: Autêntica, 2000. p. 136.

12. CHAVES, Vera Lúcia Jacob; MENDES, Odete da Cruz. REUNI: o contrato de gestão na reforma da educação superior pública. In: CABRAL NETO, Antônio; CHAVES, Vera Lúcia Jacob; NASCIMENTO, Ilma Vieira. Políticas da educação superior no Brasil: velhos temas e novos desafios. São Paulo: Xamã, 2009. p. 271.

13. CISLAGHI, Juliana Fiuza. Precarização e superexploração do trabalho docente: a expansão das matrículas e o aumento da relação professor/aluno. Universidade e Sociedade, Brasília, v. XX, n. 47, p. 165-174, fevereiro 2011.

14. DI PIETRO, Maria Sylvia Zanella. Contratos de gestão. Contratualização do controle administrativo sobre a administração indireta e sobre as organizações sociais. Revista da Procuradoria Geral do Estado de São Paulo, São Paulo, n. 45/46, jan./dez., 1996. Disponível em:<http://www.pge.sp.gov.br/centrodeestudos/revistaspge/revista2/artigo9.htm>. Acesso em: 10 jul. 2013.

15. HADDAD, Sérgio. Separação entre as perspectivas econômica e social impõe limites ao desenvolvimento latino-americano. In: KRAWCZYK, N. R.; WANDERLEY, L. E. América Latina: Estado e reformas numa perspectiva comparada. São Paulo: Cortez, 2003.

16. JEZINE, Edineide. As políticas de gestão da extensão universitária: privatização e mercantilização no ensino superior. In: CHAVES, Vera Lúcia Jacob; SILVA JR., João dos Reis. Educação superior no Brasil e diversidade regional. Belém: EDUFPA, 2008.

17. LIMA, Kátia. Contra-reforma na educação superior: de FHC a Lula. São Paulo: Xamã, 2007.

18. _. REUNI e Banco de Professor Equivalente: novas ofensivas da contra-reforma da educação superior brasileira no governo Lula da Silva. Universidade e Sociedade, Brasília, v. XVII, n. 41, p. 69-77, janeiro 2008.

19. MINTO, Lalo Watanabe. As reformas do ensino superior no Brasil: o público e o privado em questão. Campinas: Autores Associados , 2006.

20. PEREIRA, Raphael Lacerda de Alencar. Programa de Apoio a Planos de Reestruturação e Expansão das Universidades Federais Brasileiras (REUNI): repercussões na expansão da UFRN. Dissertação (Mestrado em Educação). Universidade Federal do Rio Grande do Norte, Programa de Pós-graduação em Educação: Natal: no prelo, 2012. 
21. RIBEIRO, Maria Edilene da Silva; CHAVES, Vera Lúcia Jacob. Gestão universitária: reflexões sobre o mercado como centralidade do processo educacional, 2010. Disponivel em: <http://www.anpae.org.br/iberolusobrasileiro2010/cdrom/77.pdf>. Acesso em: 16 set. 2013.

22.

A gestão gerencialista na universidade pública brasileira: o mercado como centralidade do processo educacional. In: CABRAL NETO, A.; NASCIMENTO, I. V. D.; CHAVES, V. J. Política de expansão da educação superior no Brasil: democratização às avessas. São Paulo: Xamã, 2011.

23. SAVIANI, Demerval. O Plano de Desenvolvimento da Educação. Educação e Sociedade, Campinas, v. 28, n. 100 - Especial - p. 1231-1255, outubro, 2007.

24. SGUISSARDI, Valdemar.Universidade brasileira no século XXI. São Paulo: Cortez, 2009.

25. TONEGUTTI, Cláudio Antônio; MARTINEZ, Milena. O REUNI e a precarização nas IFES. Universidade e Sociedade, Brasília, v. XVII, n. 41, p. 51-67, janeiro 2008.

26. UNESCO. Declaração Mundial sobre Educação Superior no Século XXI: Visão e Ação. Paris, 1998. Disponível em: <http://www.nepp-dh.ufrj.br/onu12-2.html>. Acesso em: 25 out. 2013.

27. Conferência Mundial sobre Ensino Superior 2009: As Novas dinâmicas do Ensino Superior e Pesquisas para a Mudança e o Desenvolvimento Social. Paris, 2009. Disponível em:<http://www.feevale.br/Comum/midias/646f3952-c261-4e13-9aae83c2b99e5c7c/Vers\%C3\%A30\%20em\%20Portugu\%C3\%AAs.pdf>. Acesso em: 10 out. 2013.

28. UNIVERSIDADE FEDERAL DO RIO GRANDE DO NORTE. Proposta de Reestruturação e expansão (REUNI). UFRN: Natal, 2007. Disponível em: <http://www.reuni.ufrn.br/categorias/index>. Acesso em: 20 jun. 2013.

29. _. Projeto de Reestruturação e Expansão (REUNI-UFRN): Relatório 2008-2012. UFRN: Natal, 2013, p. 156. 